\title{
Development of Growth Technologies for the Photonic Single Crystals by the Czochralski Method at Institute for Single Crystals, NAS of Ukraine
}

\author{
M.B. Kosmyna, B.P. Nazarenko, V.M. Puzikov and A.N. Shekhovtsov* \\ Institute for Single Crystals, NAS of Ukraine, Lenin Ave. 60, 61001, Kharkov, Ukraine
}

\begin{abstract}
The present paper briefly overviews the application of the Czochralski method for growth of a set of oxide crystals for photonics, as well as the design of equipment at the Institute for Single Crystals, NAS of Ukraine. The examples of crystal growth and their characterization are described. The simultaneous Q-switched lasing and self-Raman frequency conversion were demonstrated in Nd-doped $\mathrm{PbWO}_{4}$ and $\mathrm{PbMoO}_{4}$ crystals grown by the Czochralski method. The slope lasing efficiency obtained for a $\mathrm{PbMoO}_{4}: \mathrm{Nd}^{3+}$ laser is the best result for all the crystals with the scheelite-type structure. A detection unit with high scintillation characteristics based on a large volume $\left(V \approx 350 \mathrm{~cm}^{3}\right) \mathrm{CdWO}_{4}$ crystal was produced. Crystal growth procedures and properties of new double tungstate and vanadate crystals are presented, too.
\end{abstract}

DOI: 10.12693 /APhysPolA.124.305

PACS: $81.10 . \mathrm{Fq}, 42.70 . \mathrm{Hj}, 42.70 . \mathrm{Mp}, 29.40 . \mathrm{Mc}$

\section{Introduction}

The use of the Czochralski method at Institute for Single Crystals NAS of Ukraine (the Institute) was motivated by a need to produce laser elements for new facilities. Investigations in the field of lasers were started at the Institute as long ago as in 1961. This was a turning-point in the development of physics and optics and the change-over to optical quantum generators (OQG). Intensive investigations in the field of quantum electronics were carried out under the leadership of Nobel Prizers Prokhorov and Basov at Institute of General Physics (Moscow, Russia), USSR Academy of Sciences, and at other laser centres of the world. In Ukraine these investigations were started at Institute for Single Crystals and Institute of Physics (Kiev, Ukraine), NAS of Ukraine.

At that time, one of the main active elements for OQGs was neodymium-doped calcium tungstate single crystal $\left(\mathrm{CaWO}_{4}: \mathrm{Nd}^{3+}\right)$. The first continuous-wave laser operating at room temperature was designed on the base of this crystal at Institute of General Physics, USSR Academy of Sciences (Moscow, Russia).

The Czochralski method was the main stage of production technology of high-temperature oxide single crystals. Its potentialities were realized due to modernization of the available setups for thermal treatment of metallic machine parts. These setups were transformed into growth apparatuses and then used for the growth of $\mathrm{Y}_{3} \mathrm{Al}_{5} \mathrm{O}_{12}$ yttrium-aluminium garnet (YAG) and calcium tungstate single crystals.

The design of new facilities of "OKB-63" type according to the specifications of the Institute essentially

*corresponding author; e-mail: shekhov@isc.kharkov .ua speeded up the technological work on the growth of high-temperature single crystals. However, the most important breakthrough in the development of laser garnet crystals was made in 1972 when new-generation setups "Donets-1" (made by the design department "Donets", Ukraine) were put into operation.

Since 1972, laser elements based on YAG crystals have practically completely ousted calcium tungstate elements and became widely used in quantum electronics. Lasers and laser facilities won sound position in all branches of science and industry. At that time YAG was considered to be the best material for solid state high-efficient $\mathrm{CW}$, Q-switched and mode-locked lasers with low generation threshold [1].

\section{Application of the Czochralski method for the growth of laser crystals}

During a short period of time, specialists from the Institute developed YAG laser element technology production according to OQG specifications. The technology of YAG crystal production was introduced at an industrial plant.

While working out the growth technology there was chosen the optimal protective and reducing medium containing 98 vol.\% of $\mathrm{Ar}+2$ vol. $\%$ of $\mathrm{O}_{2}$ which provided the obtaining of crystals with high optical quality and without oxidation and failure of iridium crucibles. The developed design of crystallization unit provided the required distribution of thermal fields in the crystallization zone and the axial temperature gradient. The optical quality of the crystals was raised due to stabilization of the growth conditions achieved by means of automated control of the growth process. This allowed to decrease the diameter of bulk defect in central region of crystal to $\approx 1 \mathrm{~mm}$. Homogeneous YAG:Nd and YAG:Nd:Cr,Ce garnet crystals were obtained at a convex crystal-melt 
interface. Variations of temperature of the crucible wall due to uncontrolled fluctuations of the power supplied to the inductor and of melt temperature near the crystalmelt interface (at a depth less than $5 \mathrm{~mm}$ ) did not exceed $0.5-1{ }^{\circ} \mathrm{C}[1]$. The obtained crystals had a length of 150 $200 \mathrm{~mm}$ and a diameter of $\approx 35 \mathrm{~mm}$ (Fig. 1).

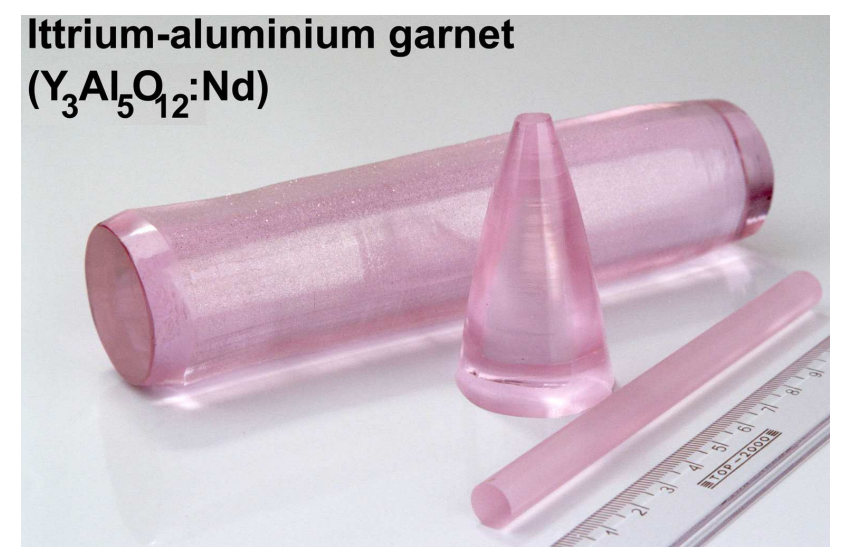

Fig. 1. $\mathrm{Y}_{3} \mathrm{Al}_{5} \mathrm{O}_{12}: \mathrm{Nd}^{3+}$ crystal and laser rod.

Due to unique capabilities of the Czochralski method growth technologies of a number of compounds were developed. In particular, the growth technology of forsterite $\left(\mathrm{Mg}_{2} \mathrm{SiO}_{4}\right)$ single crystals was developed during 1989-1993. The tunable lasers based on forsterite crystals were designed for the first time. The tunable range of laser was $1170-1330 \mathrm{~nm}$. The lasers were able to generate extra-short $25-30$ fs pulses at $250 \mathrm{~mW}$ output power and demonstrated a stable $K L M$ regime operation under the synchronous pumping.

A series of nonlinear optic crystals was grown at the Institute by means of the Czochralski method: lithium niobate $\left(\mathrm{LiNbO}_{3}\right)$, lithium tantalate $\left(\mathrm{LiTaO}_{3}\right)$, fresnoite $\left(\mathrm{Ba}_{2} \mathrm{TiSi}_{2} \mathrm{O}_{8}\right)$, $\mathrm{KTiOPO}_{4}$, and a number of borates $\left(\mathrm{LiB}_{3} \mathrm{O}_{5}, \mathrm{Li}_{2} \mathrm{~B}_{4} \mathrm{O}_{7}, \beta-\mathrm{BaB}_{2} \mathrm{O}_{4}\right)$ [2-4]. The method of growth of lithium niobate and lithium tantalate crystals developed during 1983-1985 was brought into commercial production. For the first time, photorefractive resistant lithium tantalate crystals were obtained. The value of resistance exceeded the one of the world analogues by an order of magnitude.

The top seed solution growth method (TSSG) was used at the Institute for the obtaining of nonlinear optic and laser crystals. The production technologies of neodymium and chromium doped $\mathrm{Gd}_{3} \mathrm{Sc}_{2} \mathrm{Ga}_{3} \mathrm{O}_{12}$ gadolinium scandium gallium garnets as well as neodymium doped $\mathrm{KGd}\left(\mathrm{WO}_{4}\right)_{2}$ potassium gadolinium tungstate, were developed at the Institute during 19851989. Active laser elements based on the crystals provide low threshold and high generation efficiency at low pumping energies. It allows to essentially decrease the dimensions, weight, and power consumption of laser facilities. The nonlinear optic borate single crystals $\left(\mathrm{LiB}_{3} \mathrm{O}_{5}\right.$, $\beta$ - $\mathrm{BaBO}_{4}$ ) were grown by the use of TSSG method, too.
The Institute has elaborated specifications for new equipment for growth of high-temperature oxide single crystals. High-frequency crystal growth units were designed for single crystal growth by the Czochralski method in collaboration with: "VNIITVCH" (SaintPetersburg, Russia) - generation of setups "Kristall 603, 605, 607"; TsKBM "Donets" (Lugansk, Ukraine) — setup "Landysh"; "TEKHMONTAG" (Lugansk, Ukraine) setup "Analog".

The growth of single crystals from melt by the Czochralski method has a number of advantages, such as the absence of contact between the crystal and the crucible walls, that essentially reduces stresses in the crystals; the possibility to control the crystal growth visually and the processes which occur at the crystal-melt interface, relative simplicity of its technical realization. Moreover, the method allows to grow large-size and sufficiently perfect high-melting oxide crystals, to control the character of the melt convection and as consequence - to choose the most optimal conditions for the growth of optically homogeneous crystals. Possibilities of the method are able to provide the obtaining of crystals of different shape. The morphology of crystals is illustrated by Fig. 2 .

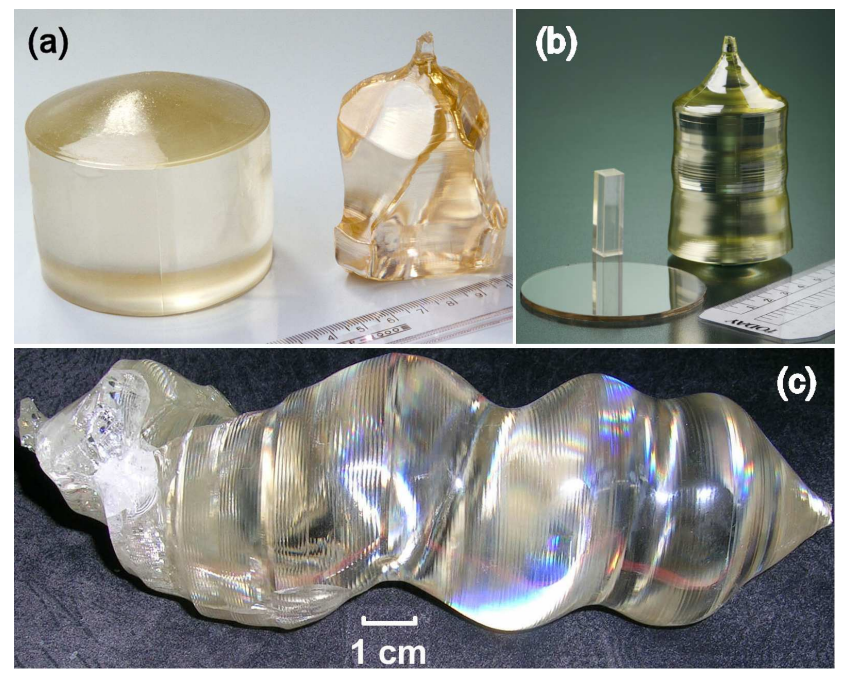

Fig. 2. The crystals grown at different vertical gradients: a $-\mathrm{LiNbO}_{4} ; \mathrm{b}-\mathrm{LiTaO}_{4} ; \mathrm{c}-\mathrm{PbWO}_{4}$.

At low vertical gradients $(\partial T / \partial z$ less than $10 \mathrm{deg} / \mathrm{cm})$ the grown lithium niobate crystals are strongly faceted (Fig. 2a), at gradients of $30 \mathrm{deg} / \mathrm{cm}$ and higher the lithium niobate and lithium tantalate crystals are of cylindrical shape (Fig. 2a, b).

The shape of large-size $\mathrm{PbWO}_{4}$ single crystals $(\emptyset \geq$ $50 \mathrm{~cm}$ ) grown along the $z$ axis was also different from cylindrical (Fig. 2c). The crystals of the preset diameter and rigorously cylindrical shape of the surface were obtained under the conditions when the ratio $d_{\text {crystal }} / D_{\text {crucible }} \leq 0.45$ held true during the whole growth process, and the axial gradients were $\partial T / \partial z \approx$ 
$25 \mathrm{deg} / \mathrm{cm}$. In the case when $0.45<d_{\text {crystal }} / D_{\text {crucible }}<$ 0.65 the crystal shape was at first cylindrical, but then it was transformed into spiral (Fig. 2c).

At the growth of $\mathrm{PbWO}_{4}$ crystals with a $50 \mathrm{~mm}$ diameter, the level of the melt decreases faster than it takes place during the growth of the crystal of a smaller diameter from the same crucible. Thereat, the crystal-melt interface descends, and the magnitude of axial gradient is decreased, too. Thus, the magnitude of axial gradient may be comparable with that of the radial gradients. A heat flow along the growth axis may essentially decrease with the rise of the growing crystal volume. The IR radiation absorption by the growing crystal can affect on a heat flow. The change of temperature distribution at crystal-melt interface as well as the crystal anisotropy of thermal conductivity may lead to the situation when the direction of the maximum heat transfer does not coincide with the growth direction. Such thermal conditions result in the formation of strong internal stresses and make the morphology of $\mathrm{PbWO}_{4}$ crystal different from cylindrical one [5].

The Institute was the first to realize the growth of YAG crystals by the Czochralski method from "cold crucible" (crucible free, combination of the Czochralski method and skull melting method) that provided the possibility of saving expensive and scarce iridium used at crucible production.

A weighing of either the crucible containing the melt or the growing crystal is generally used during the automated process of crystal growth by the Czochralski method [6]. The choice of the weighing object depends on the dimensions and total mass of the used crystallization unit. The method of weighing the melt is considered to have certain advantages when the total mass of the crystallization unit is up to $16 \mathrm{~kg}$. At present the sensitivity is $0.01 \mathrm{~g}$ at a crystallization unit mass up to $10 \mathrm{~kg}$.

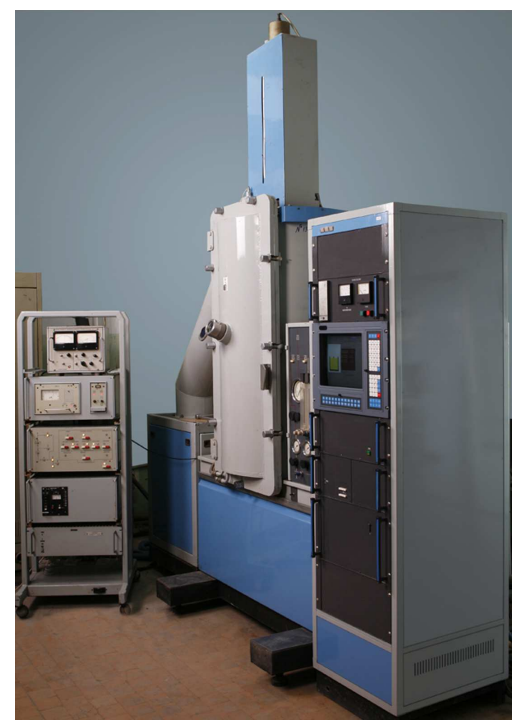

Fig. 3. Automated "Analog" apparatus under control of OS Windows.
Due to upgrading of the growth "Kristall-3M" setup a completely automated "Analog" apparatus (Fig. 3) was designed for growth of high-temperature oxide crystals by the Czochralski method. The setup allows to grow a wide range of crystals, including incongruent melting crystals or phase transition containing crystals (crystal growth from solution-melt).

\section{3. $\mathrm{PbWO}_{4}: \mathrm{Nd}^{3+}$ and $\mathrm{PbMoO}_{4}: \mathrm{Nd}^{3+}$ crystals for Raman lasers}

For the major part of solid (non-diode) state lasers the laser generation is realized by means of $f-f$ emission of rare-earth ions according to different mechanisms of energy transformation (sensibilization, cross-relaxation, cascade generation, co-operative excitation) [7]. Since the crystal field weakly affects on the $f$ state energy position, the luminescence maxima of rare earth ions slightly depend on the crystal field of host. For the laser media doped with rare earth $\left(\mathrm{RE}^{3+}\right)$ ions only one wavelength is dominant. The spectral range of such lasers is extended by means of nonlinear optical effects. One of them is the transformation of the emission wavelength due to the Raman scattering [8].

A commercial Raman laser consists of an active laser medium based on $\mathrm{Al}_{2} \mathrm{O}_{3}$ :Ti or $\mathrm{Y}_{3} \mathrm{Al}_{5} \mathrm{O}_{12}$ : $\mathrm{Nd}$ crystals and Raman converter, for example $\mathrm{Ba}\left(\mathrm{NO}_{3}\right)_{2}$ crystal. To minimize the losses and to make the design of laser apparatus simpler and cheaper, the crystal must simultaneously perform the functions of both active laser medium and Raman converter. For this purpose $\mathrm{PbWO}_{4}$ lead tungstate and $\mathrm{PbMoO}_{4}$ lead molybdate are the most promising crystals [9]. Due to congruent melting of $\mathrm{PbWO}_{4}\left(1141^{\circ} \mathrm{C}\right)$ and $\mathrm{PbMoO}_{4}\left(1060^{\circ} \mathrm{C}\right)$, it is possible to successfully use the Czochralski method and to carry out the growth from platinum crucibles.

One of the problems arising at the growth of tungstates and molybdates of alkali earth element crystals is non-stoichiometric evaporation of melt, in particular, of tungsten and molybdenum oxides. This gives rise to changes in the melt composition, the formation of various point defects and their aggregation in the crystals. It leads to an essential variation of the physico-chemical properties along the crystal length. To reduce the influence of these negative factors, an excess of tungsten (molybdenum) oxide (of about 1-3 mass\%) is introduced into the initial charge before crystal growth. Moreover, certain efforts are taken to reduce an overheating of melt. To prevent an overheating of melt, different crystallization units containing passive and active afterheaters, gas composition, and pressure in the growth chamber are used.

Another problem is the obtaining of crystals to be used as active elements of lasers with diode pumping. In this case, in contrast to lasers with flash-lamp pumping, the elements containing laser-active ions (e.g. $\mathrm{Nd}^{3+}$ ) which absorb 70-90\% of the pumping energy at several millimetre length are required. Due to considerable 
ionic radius mismatch, the growth of heavily neodymium doped alkali-earth tungstate and molybdate single crystals with optical and structural homogeneity is a sophisticated problem.

Experimental choice of the growth conditions allowed to successfully apply the Czochralski method for the crystal growth and production of active elements for the Raman lasers. We obtained $\mathrm{Nd}^{3+}$ doped $\mathrm{PbWO}_{4}$ and $\mathrm{PbMoO}_{4}$ crystals with a diameter of $25-30 \mathrm{~mm}$ and a length up to $200 \mathrm{~mm}$. The $\mathrm{Nd}^{3+}$ concentration in $\mathrm{PbWO}_{4}$ and $\mathrm{PbMoO}_{4}$ crystals was up to 2 mass $\%$ and up to 3 mass \%, respectively (Fig. 4) [10, 11].

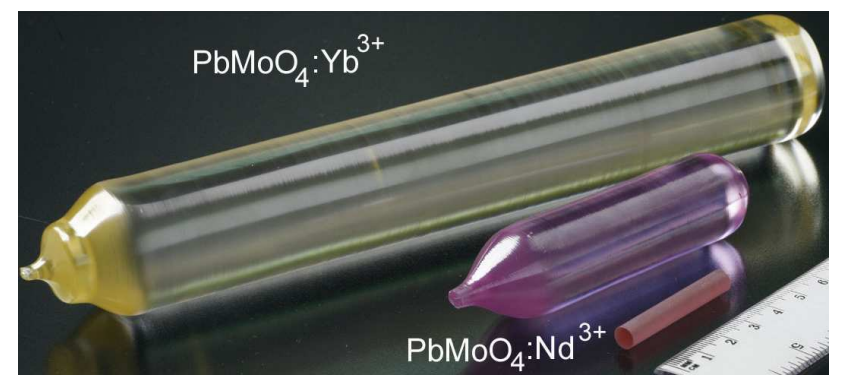

Fig. 4. $\mathrm{PbMoO}_{4}$ single crystals and laser rod.

Experimental investigations of laser oscillations in $\mathrm{PbWO}_{4}: \mathrm{Nd}^{3+}$ and $\mathrm{PbMoO}_{4}: \mathrm{Nd}^{3+}$ crystals under different pumping sources were carried out. Figure 5 presents the dependence of laser output energy on pumping energy of diode laser for neodymium doped $\mathrm{PbWO}_{4}: \mathrm{Nd}^{3+}$ lead tungstate and $\mathrm{PbMoO}_{4}: \mathrm{Nd}^{3+}$ lead molybdate single crystals.

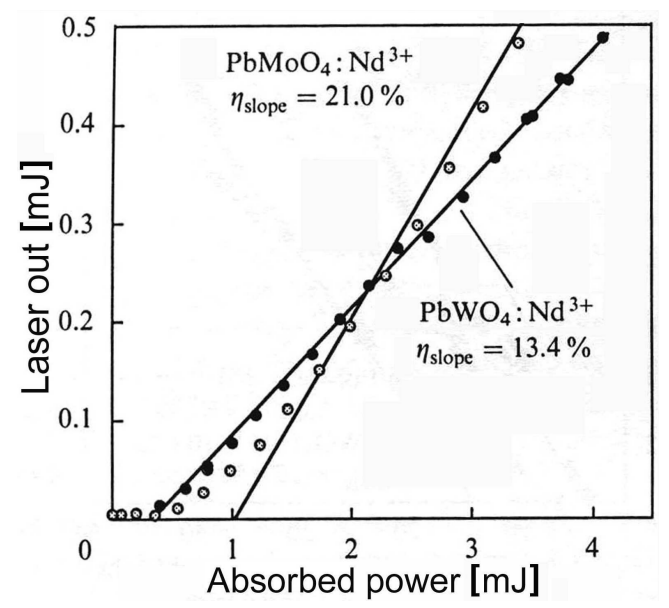

Fig. 5. Dependence of the output energy on the diode laser pumping energy for $\mathrm{PbWO}_{4}: \mathrm{Nd}^{3+}$ and $\mathrm{PbMoO}_{4}: \mathrm{Nd}^{3+}$ crystals.

Under diode laser pumping the $0.47 \mathrm{~mJ}$ generation threshold and the $13.4 \%$ slope efficiency were achieved for $\mathrm{PbWO}_{4}: \mathrm{Nd}^{3+}$ crystal based laser. The $21 \%$ slope efficiency obtained for $\mathrm{PbMoO}_{4}: \mathrm{Nd}^{3+}$ was the highest among the crystals with the scheelite-type structure (Fig. 5) [12].

The analysis of oscillation properties of tungstate and molybdate crystals with the structure of scheelite-type under alexandrite and diode laser pumping testifies that the highest slope efficiency is achieved for $\mathrm{PbWO}_{4}: \mathrm{Nd}^{3+}$ and $\mathrm{PbMoO}_{4}: \mathrm{Nd}^{3+}$ crystals. The crystals with such structure type are characterized by higher peak Raman cross-sections, lower SRS thresholds, higher Raman gain, and greater Raman conversion efficiency in comparison with those of commercial $\mathrm{KGd}\left(\mathrm{WO}_{4}\right)_{2}: \mathrm{Nd}$ crystal.

For the $\mathrm{PbWO}_{4}: \mathrm{Nd}^{3+}$ and $\mathrm{PbMoO}_{4}: \mathrm{Nd}^{3+}$ based lasers in the passively $Q$-switched mode laser generation was realized simultaneously with SRS conversion [12, 13]. For $\mathrm{PbMoO}_{4}: \mathrm{Nd}^{3+}$ laser self Raman operation at $1163 \mathrm{~nm}$ (1st Stokes) was achieved for the first time [13].

A new compound was revealed while studying the quasi-binary system $\mathrm{PbMoO}_{4}+\mathrm{Nd}_{2}\left(\mathrm{MoO}_{4}\right)_{3}$. For the first time, a series of experiments resulted in the obtaining of $\mathrm{PbNd}_{4}\left(\mathrm{MoO}_{4}\right)_{7}$ single crystals by the Czochralski method from the melt of the stoichiometric composition. The crystals with a diameter up to $20 \mathrm{~mm}$ and a length up to $40 \mathrm{~mm}$ were grown from platinum crucibles in air (Fig. 6) [14].

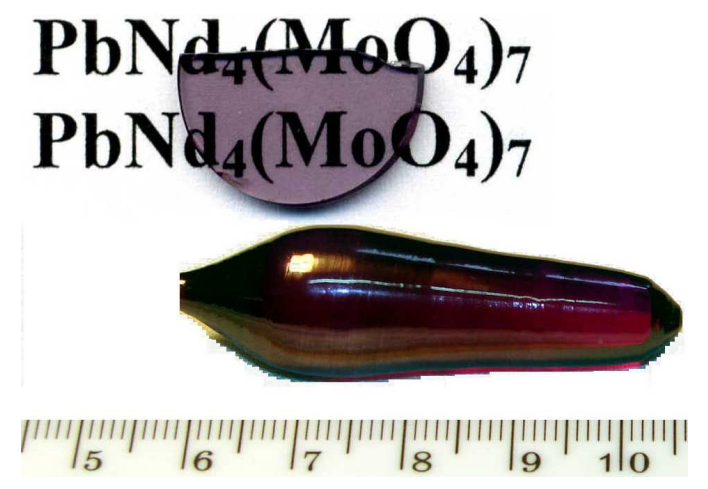

Fig. 6. $\operatorname{PbNd}_{4}\left(\mathrm{MoO}_{4}\right)_{7}$ single crystals.

The structure interpretation of $\mathrm{PbNd}_{4}\left(\mathrm{MoO}_{4}\right)_{7}$ single crystal showed that the compound belongs to monoclinic system, the space group $C 2 / c$. The unit cell parameters are: $a=16.8585 \AA, b=11.8022 \AA, c=11.8529 \AA$, $\beta=98.080^{\circ}$. Cations of lead and neodymium are coordinated by eight oxygen atoms, whereas molybdenum cations are linked with four oxygen atoms. Neodymium cations occupy two crystallographic positions. The unit cell of $\mathrm{PbNd}_{4}\left(\mathrm{MoO}_{4}\right)_{7}$ crystal is presented in Fig. 7 .

Due to spatial separation of neodymium cations in the crystal lattice, concentration quenching of $f-f$ luminescence of $\mathrm{Nd}^{3+}$ ions is reduced. Investigation of $\mathrm{Nd}^{3+}$ luminescence decay kinetics shows that the luminescence decay curve is approximated by the sum of two components with the times $\tau_{1}=1.1 \mu \mathrm{s}$ and $\tau_{2}=3.5 \mu \mathrm{s}$. The presence of two decay times points to the existence of two luminescence centres with non-equivalent $\mathrm{Nd}^{3+}$ surrounding and confirms the data of X-ray structure anal- 


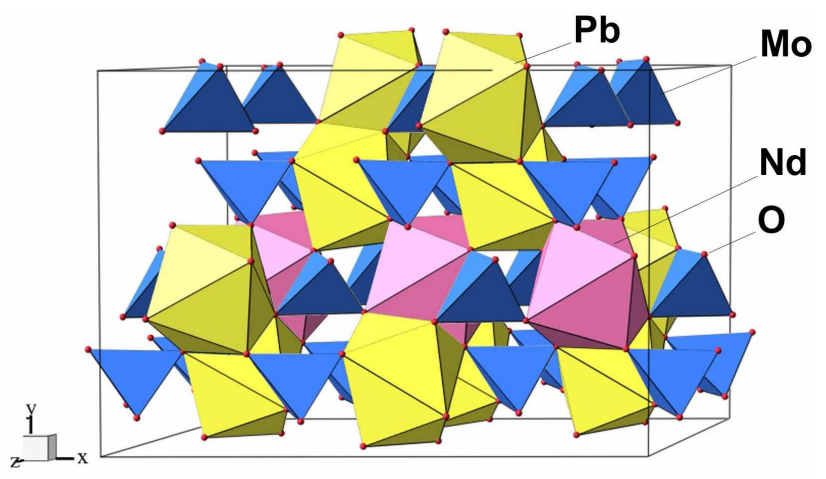

Fig. 7. Unit cell of $\mathrm{PbNd}_{4}\left(\mathrm{MoO}_{4}\right)_{7}$ crystal.

ysis which shows that $\mathrm{Nd}^{3+}$ cations can occupy not only their own crystallographic position, but also the one of lead [14]. Thus, the new $\mathrm{PbNd}_{4}\left(\mathrm{MoO}_{4}\right)_{7}$ crystal may add to the series of self-concentrated crystal hosts for active laser media.

\section{Scintillation single crystals}

\section{1. $\mathrm{PbWO}_{4}$ crystals}

The Czochralski method was considered to be the most suitable for large-scale industrial production of $\mathrm{PbWO}_{4}$ crystals. In particular, it was used to provide huge amounts of these crystals (about 100000 scintillation elements) for the CMC and ALICE projects at CERN [15].

A crystal growth technology of large-size $\mathrm{PbWO}_{4}$ crystals (35 $\mathrm{mm}$ in diameter and $250 \mathrm{~mm}$ long) for scintillation detectors was developed at Institute. It is characterized by comprehensive approach to technological preparation of the starting material (including re-crystallization) and to the doping of the crystals with different ions for the formation of preset properties, such as maximum position of luminescence spectrum, radiation hardness, absence of colour centres which re-absorb the host luminescence [15].

Experimental investigations of $\mathrm{PbWO}_{4}$ crystal growth were carried out by use of the setups with high-frequency heating "Crystal 3M" and "Analog". Lead tungstate crystals were grown by the Czochralski method from platinum crucibles in an atmosphere with a composition close to that of air or inert gases. At first the homogeneous mechanical mixture of tungsten and lead oxides $(99.999 \%$ purity) was melted to increase the density and perform preliminary synthesis.

For additional purification, averaging of the chemical composition, as well as for reducing the deviation from the stoichiometry, the charge was preliminarily re-crystallized. During successive crystallization processes the melt composition is being corrected, the doping is realized taking into account the measurements of the parameters of the scintillation elements. Lanthanum, yttrium or niobium doped $\mathrm{PbWO}_{4}$ crystals were grown. The dopant concentration was few tens of ppm. The single crystals and rectangular scintillation elements are shown in Fig. 8.

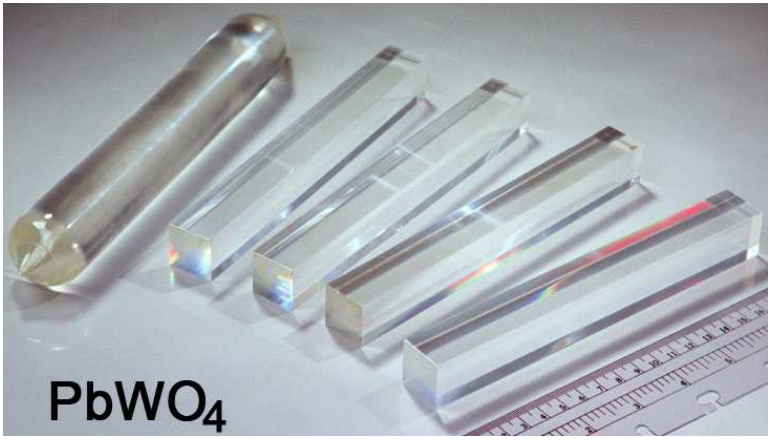

Fig. 8. $\mathrm{PbWO}_{4}$ single crystal and scintillation elements.

The Czochralski method was successively applied for crystal growth where the formation of preset properties was achieved by modification of both the cationic and anionic sublattices. Experimental choice of growth conditions and dopants for modification of the cationic and anionic sublattices of $\mathrm{PbWO}_{4}$ crystal allows to control the properties of these crystals within wide range, in particular, to vary the luminescence kinetics and position of host luminescence maximum and to achieve essential increase of light yield or radiation hardness, for example [16-18].

\section{2. $\mathrm{CdWO}_{4}$ crystals}

At present time, multi-energy radiation control systems containing multi-element scintillation detectors based on cadmium tungstate crystals are actively developed. The new generation of devices formulates stringent requirements for scintillation assemblies based on cadmium tungstate crystals. Each detector array meant for introscopic systems requires several thousands elements with high identity of scintillation parameters.

The growth technology of $\mathrm{CdWO}_{4}$ crystals for scintillation detection unit and elements of detector arrays with preset dimensions was developed at the Institute.

As mentioned earlier, the main problem arising at the growth of these crystals is evaporation of the melt which leads to $\approx 2-3 \%$ losses of the melt weight. We carried out investigations aimed at minimization of the melt surface area due to the growth of crystals with largest possible diameter from a crucible of relatively small size. The growth of large $\mathrm{CdWO}_{4}$ crystals with a diameter approaching the crucible diameter $(100 \mathrm{~mm})$ makes it possible to decrease evaporation of the melt at high temperatures, since in this case the melt surface area not covered by the growing crystal, is minimized.

Certain corrections were introduced into the growth technology, in particular, in the composition of charge and the temperature distribution inside the crystallization unit. That allowed to reproducibly obtain high-quality colourless $\mathrm{CdWO}_{4}$ crystals with a diameter up 


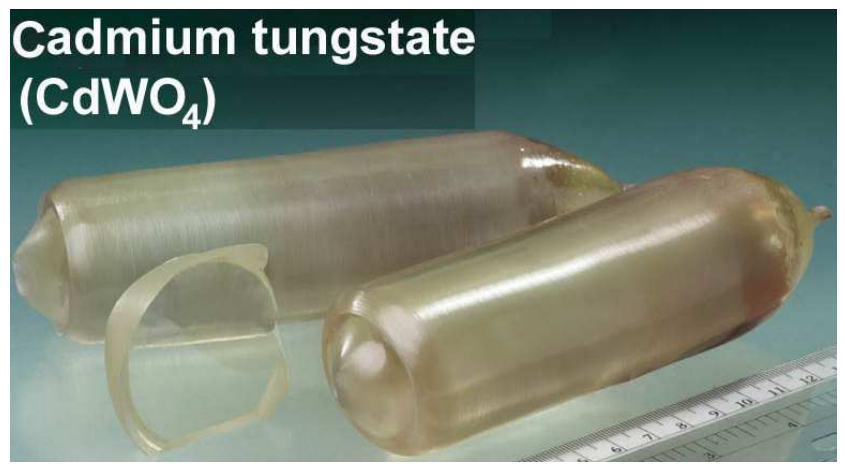

Fig. 9. $\mathrm{CdWO}_{4}$ single crystals.

to $65 \mathrm{~mm}$ and a length up to $160 \mathrm{~mm}$ from the melt of $\approx 800 \mathrm{~cm}^{3}$ volume (Fig. 9) [19]. The growth of crystals with high optical homogeneity and strictly specified dimensions made possible the reproduction of scintillation elements for detector arrays at minimum losses of material.

The large-volume $\left(\approx 350 \mathrm{~cm}^{3}\right)$ scintillation detection unit with high $(\approx 16 \%)$ energy resolution $\left({ }^{137} \mathrm{Cs}, E=\right.$ $662 \mathrm{keV}$ ) was designed in the Institute for the first time due to developed growth technology of optically homogeneous and perfect $\mathrm{CdWO}_{4}$ crystals. The detection unit can be applied high-efficient gamma-spectrometric portals that can detect neutrons, too.

\section{Growth of new $\mathrm{CdRE}_{2}\left(\mathrm{WO}_{4}\right)_{4}$ $(\mathrm{RE}=\mathrm{La}, \mathrm{Gd})$ single crystals}

With the purpose of widening the scintillation crystal family, the search for new compounds was done. According to the crystal chemistry approach, new phases can be obtained by transformation of known phase by means of change of its composition. Double tungstates may be considered as a result of modification of the cationic or anionic sublattices. Thereat, the phases of substitution, subtraction and incorporation can be formed.

Due to congruent melting and the absence of polymorphic transformations of the synthesized stoichiometric compounds $\mathrm{CdLa}_{2}\left(\mathrm{WO}_{4}\right)_{4}$ and $\mathrm{CdGd}_{2}\left(\mathrm{WO}_{4}\right)_{4}$ the Czochralski method was used for single crystal growth. The growth process of $\mathrm{CdLa}_{2}\left(\mathrm{WO}_{4}\right)_{4}$ and $\mathrm{CdGd}_{2}\left(\mathrm{WO}_{4}\right)_{4}$ crystals can be carried out in air from platinum crucibles because of melting temperatures $1090^{\circ} \mathrm{C}$ and $1166^{\circ} \mathrm{C}$, respectively. The crystallization unit specially developed for the obtaining of $\mathrm{CdWO}_{4}$ crystals was used to grow $\mathrm{CdLa}_{2}\left(\mathrm{WO}_{4}\right)_{4}$ and $\mathrm{CdGd}_{2}\left(\mathrm{WO}_{4}\right)_{4}$ single crystals. This unit contains the system of active and passive afterheaters which provide the optimum distribution of temperature in the zone of growth and subsequent annealing of the obtained crystal. The design of such unit permits to essentially reduce evaporation of melt and grow a boule with a volume up to $70 \%$ of melt volume.

The authors carried out a series of experimental growth of the crystals at varying temperature conditions. As a result, $\mathrm{CdLa}_{2}\left(\mathrm{WO}_{4}\right)_{4}$ and $\mathrm{CdGd}_{2}\left(\mathrm{WO}_{4}\right)_{4}$ crystals were grown for the first time. The diameter was up to $20 \mathrm{~mm}$ and a length - up to $40 \mathrm{~mm}$ (Fig. 10).

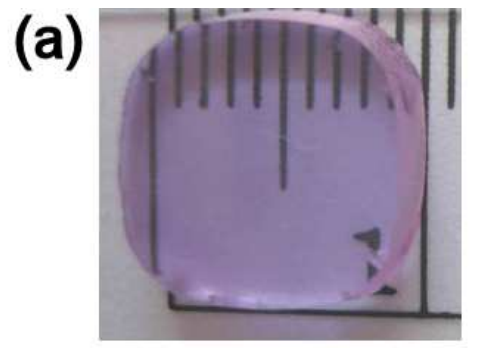

(c)
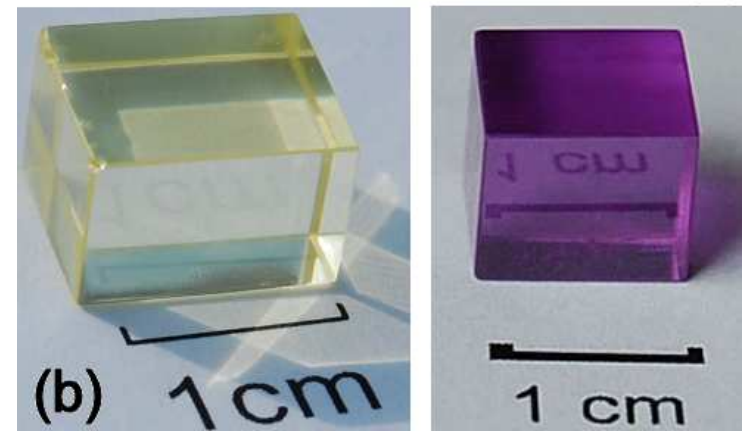

Fig. 10. Fragments of $\begin{gathered}\mathrm{CdLa}_{2}\left(\mathrm{WO}_{4}\right)_{4} \\ \text { crystals: and }\end{gathered}$ a CdGd $_{2}\left(\mathrm{WO}_{4}\right)_{4}$ single
$\mathrm{CdLa}_{2}\left(\mathrm{WO}_{4}\right)_{4}: \mathrm{Nd}^{3+}, \quad \mathrm{b}-\mathrm{CdGd}_{2}\left(\mathrm{WO}_{4}\right)_{4}, \quad \mathrm{c}-$ $\mathrm{CdGd}_{2}\left(\mathrm{WO}_{4}\right)_{4}: \mathrm{Nd}^{3+}$.

The study of their scintillation characteristics showed that the light yield of $\mathrm{CdGd}_{2}\left(\mathrm{WO}_{4}\right)_{4}$ is extremely low. It is less than $1 \%$ that of $\mathrm{CdWO}_{4}$ crystal. Though the light yield of $\mathrm{CdLa}_{2}\left(\mathrm{WO}_{4}\right)_{4}$ crystal is on the level of $23 \% \mathrm{CdWO}_{4}$ light yield, their luminescence characteristics turn out to be instable with time. In several months the light yield of $\mathrm{CdLa}_{2}\left(\mathrm{WO}_{4}\right)_{4}$ dropped dramatically and was also less than $1 \%$.

Nevertheless, we showed the possibility of $\mathrm{CdLa}_{2}\left(\mathrm{WO}_{4}\right)_{4}$ and $\mathrm{CdGd}_{2}\left(\mathrm{WO}_{4}\right)_{4}$ crystal growth. Further improvement of $\mathrm{CdLa}_{2}\left(\mathrm{WO}_{4}\right)_{4}$ and $\mathrm{CdGd}_{2}\left(\mathrm{WO}_{4}\right)_{4}$ crystal growth technology and the presence of ${ }^{116} \mathrm{Cd}$ and ${ }^{180} \mathrm{~W}$ isotopes in their composition may provide successful use of the crystals in studies of rare nuclear reactions, such as the $2 \beta$ decay [20].

To test the lasing properties of disordered $\mathrm{CdRE}_{2}\left(\mathrm{WO}_{4}\right)_{4} \quad(\mathrm{RE}=\mathrm{La}, \mathrm{Gd})$ double tungstates we grew the $\mathrm{Nd}^{3+}$-doped crystals (Fig. 10a, c). Some characteristics of $\mathrm{CdLa}_{2}\left(\mathrm{WO}_{4}\right)_{4}: \mathrm{Nd}^{3+}$ and $\mathrm{CdGd}_{2}\left(\mathrm{WO}_{4}\right)_{4}: \mathrm{Nd}^{3+}$ are presented in Table.

TABLE

Spectral, kinetic and lasing characteristics of $\mathrm{CdLa}_{2}\left(\mathrm{WO}_{4}\right)_{4}: \mathrm{Nd}^{3+}$ and $\mathrm{CdGd}_{2}\left(\mathrm{WO}_{4}\right)_{4}: \mathrm{Nd}^{3+}$ crystals.

\begin{tabular}{l|c|c|c|c}
\hline \hline & $\begin{array}{c}C_{\mathrm{Nd}} \\
{[\mathrm{mass} \%]}\end{array}$ & $\begin{array}{c}\tau[\mu \mathrm{s}] \\
(\lambda=1064 \mathrm{~nm})\end{array}$ & $\begin{array}{c}\text { Optical } \\
\text { breakdown } \\
{\left[\mathrm{J} / \mathrm{cm}^{2}\right]}\end{array}$ & $\begin{array}{c}\text { Slope } \\
\text { efficiency } \\
\eta_{\mathrm{s} 1}[\%]\end{array}$ \\
\hline $\mathrm{CdLa}_{2}\left(\mathrm{WO}_{4}\right)_{4}$ & 0.9 & 130 & 61 & - \\
$\mathrm{CdGd}_{2}\left(\mathrm{WO}_{4}\right)_{4}$ & 1 & 90 & 52 & 1.3
\end{tabular}


Laser oscillations in free-running mode under laser diode pumping for $\mathrm{CdGd}_{2}\left(\mathrm{WO}_{4}\right)_{4}: \mathrm{Nd}^{3+}$ crystals were obtained. The slope efficiency was $1.3 \%$. Laser oscillations were not observed for $\mathrm{CdLa}_{2}\left(\mathrm{WO}_{4}\right)_{4}: \mathrm{Nd}^{3+}$ crystal.

\section{Double vanadate single crystals: growth and properties}

An interest in double vanadate crystals of $\mathrm{Ca}{ }_{9} \mathrm{RE}\left(\mathrm{VO}_{4}\right)_{7}$ type is caused by the use of such crystal hosts for laser engineering and nonlinear optics. The crystals belong to the noncentrosymmetric space group $R 3 c$, therefore they can be applied for the second harmonic generation (SHG). A quantitative estimation of SHG efficiency for polycrystalline $\mathrm{Ca}_{9} \mathrm{RE}\left(\mathrm{VO}_{4}\right)_{7} \mathrm{sam}-$ ples (with $3-5 \mu \mathrm{m}$ grain dispersion) was made in [21]. The SHG efficiency in the crystals of $\mathrm{Ca}{ }_{9} \mathrm{RE}\left(\mathrm{VO}_{4}\right)_{7}$ family was shown to be by 20-40 times higher in comparison with that of quartz.

The compounds $\mathrm{Ca} 9 \mathrm{RE}\left(\mathrm{VO}_{4}\right)_{7}(\mathrm{RE}=\mathrm{Y}, \mathrm{La}, \mathrm{Gd})$ are congruently melted at $T_{\text {melt }} \approx 1500{ }^{\circ} \mathrm{C}$. Moreover, these crystals are characterized by the polymorphic transition from the noncentrosymmetric to the centrosymmetric phase [21]. The phase transition temperatures lie within $800-1100^{\circ} \mathrm{C}$ range.

The crystals with high optical nonlinearity are considered as promising active laser media. The use of diode pumping imposes certain requirements to active laser elements. In this aspect, double vanadate crystals have a number of advantages.

Disordering of $\mathrm{Ca}_{9} \mathrm{RE}\left(\mathrm{VO}_{4}\right)_{7}$ crystal structure must result in the widening of dopant spectral bands. Thereat, the wavelength temperature stability of diode laser at pumping of the crystals containing ions with narrow absorption bands, like $\mathrm{Nd}^{3+}$, is not so critical.

At $\mathrm{Yb}^{3+}$ doping such crystal host may show amplification in a wide spectral band and produce ultra-short laser pulses [22]. Moreover, high level of laser-active ions doping can be achieved for such hosts. This will allow to provide high coefficient of pumping energy absorption at a small laser element depth and, consequently, to miniaturize the laser apparatus.

Due to peculiarities of the structure of $\mathrm{Ca}_{9} \mathrm{RE}\left(\mathrm{VO}_{4}\right)_{7}$ vanadates, we can select pairs of rare-earth cations (cation of host + activator cation) and control their distribution to the crystallographic positions, thus creating different activator centres. The spatially separated polyhedrons in the crystal structure of vanadates containing rare-earth cation will reduce the exchange interaction between the activator ions and increase their concentration in the crystal without luminescence quenching [23].

Owing to the presence of vacant positions in the crystal structure, these vanadates are distinguished by high ionic conductivity and diffusion caused by migration of the ions into the cationic sublattices [24].

A number of papers devoted to the growth of $\mathrm{Ca}_{9} \mathrm{RE}\left(\mathrm{VO}_{4}\right)_{7}(\mathrm{RE}=\mathrm{Y}, \mathrm{La}, \mathrm{Gd})$ crystals and investigation of their spectroscopic properties at $\mathrm{Nd}^{3+}$-doping were published during the past ten years [25-27]. The authors of [25-27] have grown the crystals by direct pulling from the melt using the Czochralski method. However, strong scattering of laser beam passing through the crystal bulk is an essential problem limiting the use of such crystals for nonlinear optics and lasers. The causes of the scattering, though being actively discussed, have not been elucidated so far.

The growth of double vanadate $\mathrm{Ca}_{9} \mathrm{RE}\left(\mathrm{VO}_{4}\right)_{7}(\mathrm{RE}=$ Y, La, Gd) single crystals and the study of their properties were also carried out at the Institute. Taking into account their high melting temperature $\left(\approx 1500{ }^{\circ} \mathrm{C}\right)$, the crystals were grown in argon or nitrogen atmosphere in Ir crucibles $(\emptyset=60 \mathrm{~mm}, h=70 \mathrm{~mm})$ by means of "Kristall 3M" and "Analog" setups with inductive heating and an automated control diameter system of growing crystal. The crystal growth was carried out along the crystallographic axis [001].

Under the described conditions nominally pure and doped $\mathrm{Ca}_{9} \mathrm{RE}\left(\mathrm{VO}_{4}\right)_{7}(\mathrm{RE}=\mathrm{Y}, \mathrm{La}, \mathrm{Gd})$ single crystals were grown. The growth process is reported in detail in [28]. According to the data of chemical analysis, the total concentration of uncontrolled impurities in each crystal was not higher than $(2-3) \times 10^{-3}$ mass\%. The crystals had a diameter up to $25 \mathrm{~mm}$ and a length up to $80 \mathrm{~mm}$.

The scattering centres in crystals were studied by means of optical and electron microscopy. According to the obtained data, the crystals did not contain micronand submicron-size gaseous phase inclusions. Neither inclusions of the crucible material (iridium) nor micro cracks were observed. At the same time, the energy dispersive X-ray analysis of crystals showed inhomogeneity of composition. Within the crystal, inclusions of several micrometer sizes with a distinct compositional contrast were observed. According to the element analysis, these inclusions were enriched with a rare-earth element. The maximum density of the enriched regions was observed for $\mathrm{Ca}_{9} \mathrm{Gd}\left(\mathrm{VO}_{4}\right)_{7}$ crystal [28].

On the basis of crystals structure peculiarities of $\mathrm{Ca} 9 \mathrm{RE}\left(\mathrm{VO}_{4}\right)_{7}$ compounds and aiming at the obtaining of single crystals with homogeneous composition, we made an attempt to grow $\mathrm{Ca}_{10} \mathrm{Me}\left(\mathrm{VO}_{4}\right)_{7}(\mathrm{Me}=\mathrm{Li}, \mathrm{Na}, \mathrm{K})$ single crystals. The crystal lattice of $\mathrm{Ca}_{10} \mathrm{Me}\left(\mathrm{VO}_{4}\right)_{7}(\mathrm{Me}=$ $\mathrm{Li}, \mathrm{Na}, \mathrm{K})$ compounds does not contain vacant crystallographic positions. The regimes and conditions were the same as for $\mathrm{Ca}_{9} \mathrm{RE}\left(\mathrm{VO}_{4}\right)_{7}$ crystal growth. Thus, the $\mathrm{Ca}_{10} \mathrm{M}\left(\mathrm{VO}_{4}\right)_{7}(\mathrm{M}=\mathrm{Li}, \mathrm{Na}, \mathrm{K})$ single crystals were grown for the first time. Fragments of crystals are shown in Fig. 11.

On the base of obtained data on scattering centers, real compositions of obtained double vanadate crystals and growth conditions, the compositions of crystals were experimentally selected, and a number of $\mathrm{Nd}^{3+}, \mathrm{Yb}^{3+}$ and $\mathrm{Er}^{3+}$-doped single crystals were grown.

Preliminary experimental study of laser oscillation allowed to obtain $0.87 \%$ slope efficiency for $\mathrm{Ca}_{10} \mathrm{Li}\left(\mathrm{VO}_{4}\right)_{7}: \mathrm{Nd}^{3+}$ crystal at flash-lamp pumping in free-running mode (Fig. 12). Thereat, the $\mathrm{Nd}^{3+}$ con- 


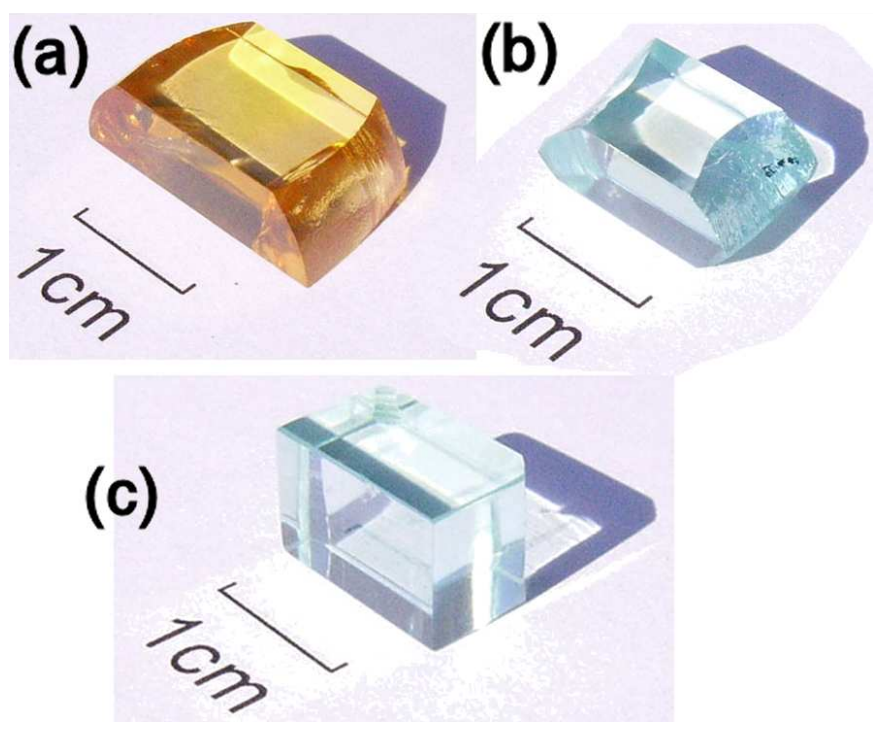

Fig. 11. Fragments of double vanadate crystals: a $\mathrm{Ca}_{10} \mathrm{Li}\left(\mathrm{VO}_{4}\right)_{7}, \mathrm{~b}-\mathrm{Ca}_{10} \mathrm{Na}\left(\mathrm{VO}_{4}\right)_{7}, \mathrm{c}-\mathrm{Ca}_{10} \mathrm{~K}\left(\mathrm{VO}_{4}\right)_{7}$.

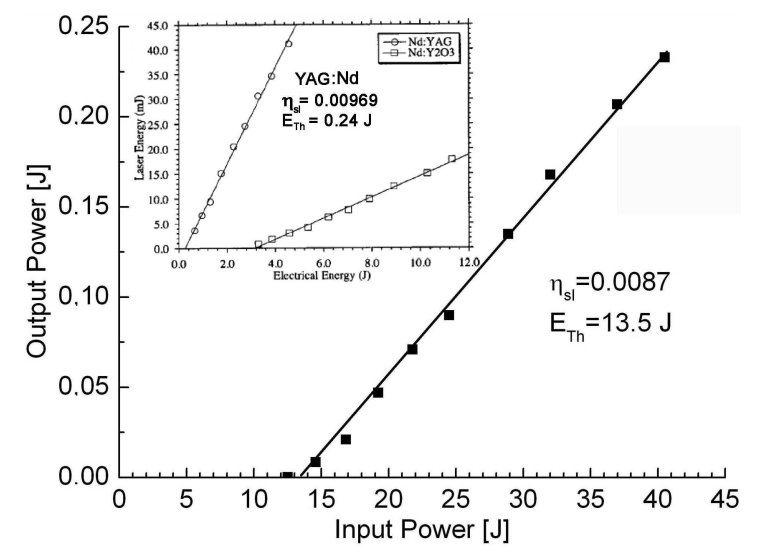

Fig. 12. Laser output of $\mathrm{Ca}_{10} \mathrm{Li}\left(\mathrm{VO}_{4}\right)_{7}: \mathrm{Nd}^{3+}$ crystals vs. the electrical flash-lamp energy. Inset - laser output of $\mathrm{Y}_{3} \mathrm{Al}_{5} \mathrm{O}_{12}: \mathrm{Nd}^{3+}$ and $\mathrm{Y}_{2} \mathrm{O}_{3}: \mathrm{Nd}^{3+}$ crystals from Ref. [29].

centration and the laser generation conditions were not optimal. Nevertheless, the obtained efficiency value is close to that of commercial $\mathrm{Y}_{3} \mathrm{Al}_{5} \mathrm{O}_{12}: \mathrm{Nd}^{3+}$ crystal and exceeds the efficiency of $\mathrm{Y}_{2} \mathrm{O}_{3}: \mathrm{Nd}^{3+}$ at flash-lamp pumping in free-running mode (the inset in Fig. 12) [29].

Thus, taking into account physico-chemical investigations, we obtained new single crystal hosts for nonlinear optics and laser engineering by means of the Czochralski method [30].

\section{Conclusions}

Using the Czochralski method during the whole period of the existence of Institute for Single Crystals, NAS of Ukraine the specialists from the Institute obtained a large number of laser, nonlinear optical and scintillation crys- tals and developed industrial highly efficient technologies of crystal growth.

Five generations of crystal growth setups were designed according to specifications of the Institute. The method was used for the growth of approximately 30 types of oneand multi-component single crystals.

The Czochralski method permits easily change of the thermal fields and crystal growth conditions, to control the dimensions and shape of the growing crystals. This makes the method unique and suitable for the obtaining of crystals, such as $\mathrm{Si}, \mathrm{Ge}, \mathrm{Y}_{3} \mathrm{Al}_{5} \mathrm{O}_{12}: \mathrm{Nd}, \mathrm{Al}_{2} \mathrm{O}_{3}: \mathrm{Ti}$, $\mathrm{CdWO}_{4}, \mathrm{PbWO}_{4}, \mathrm{Bi}_{3} \mathrm{Ge}_{5} \mathrm{O}_{12}$, etc. for both, scientific research and a number of commercial applications.

The Czochralski method is universal and widely used. At present it is successfully applied for the obtaining of a wide range of crystals with different composition and melting temperature, that makes a valuable contribution to the development of Hi-Tech industry.

\section{References}

[1] Handbook of Lasers, Ed. F. Trager, Springer-Verlag, Berlin 2012.

[2] M.B. Kosmyna, A.P. Voronov, S.F. Prokopovich, O.P. Balva, USSR Patent \#807688, 20.07.1979.

[3] M.B. Kosmyna, A.B. Levin, A.I. Mashkov, N.F. Efremova, Russian Federation Patent \#1468025, 21.07.1987.

[4] V.A. Aslanov, M.B. Kosmyna, A.A. Frolov, O.B. Struver, Russian Federation Patent \#1568593, 28.06.1988.

[5] Yu.N. Gorobets, M.B. Kosmyna, B.P. Nazarenko, A.N. Shekhovtsov, Funct. Mater. 13, 400 (2006).

[6] D. Mateika, in: Current Topics in Materials Science, Vol. 11, Ed. E. Kaldis, North-Holland, Amsterdam 1984, p. 153.

[7] Handbook of Lasers, Ed. M.J. Weber, CRC Press LLC, Boca Raton 2001.

[8] R.C. Powell, T.T. Basiev, in: Handbook of Laser Technology and Applications, Eds. J.D.C. Jones, C.E. Webb, Taylor\&Francis Group, CRC Press, Boca Raton 2003, p. 467.

[9] T.T. Basiev, Phys. Usp. 42, 1051 (1999).

[10] V.N. Baumer, Yu.T. Dynnik, M.B. Kosmyna, B.P. Nazarenko, V.M. Puzikov, A.N. Shekhovtsov, V.F. Tkachenko, Opt. Mater. 30, 106 (2006).

[11] Yu.N. Gorobets, M.B. Kosmyna, A.P. Luchechko, B.P. Nazarenko, V.M. Puzikov, A.N. Shekhovtsov, D.Yu. Sugak, J. Cryst. Growth 318, 687 (2011).

[12] T.T. Basiev, M.E. Doroshenko, L.I. Ivleva, V.V. Osiko, M.B. Kosmyna, V.K. Komar, J. Sulc, H. Jelinkova, Quant. Electron. 36, 720 (2006).

[13] T.T. Basiev, S.V. Vassiliev, M.E. Doroshenko, V.V. Osiko, V.M. Puzikov, M.B. Kosmyna, Opt. Lett. 31, 65 (2006).

[14] T.T. Basiev, V.N. Baumer, Yu.N. Gorobets, M.E. Doroshenko, M.B. Kosmyna, B.P. Nazarenko, V.V. Osiko, V.M. Puzikov, A.N. Shekhovtsov, Cryst. Rep. 54, 697 (2009). 
[15] P. Lecoq, A. Annenkov, A. Gektin, M. Korzhik, C. Pedrini, Inorganic Scintillator for Detector Systems, Springer-Verlag, Berlin 2006.

[16] B.V. Grinyov, M.B. Kosmyna, V.R. Lyubinskiy, B.P. Nazarenko, P.V. Nomokonov, V.M. Puzikov, A.S. Vodopianov, Funct. Mater. 8, 729 (2001).

[17] V.N. Baumer, Yu.N. Gorobets, O.V. Zelenskaya, M.B. Kosmyna, B.P. Nazarenko, V.M. Puzikov, A.N. Shekhovtsov, Cryst. Rep. 53, 1252 (2008).

[18] N.R. Krutyak, V.V. Mikhailin, D.A. Spassky, V.N. Kolobanov, M.B. Kosmyna, B.P. Nazarenko, V.M. Puzikov, A.N. Shekhovtsov, J. Appl. Spectr. 79, 228 (2012).

[19] M.B. Kosmyna, B.P. Nazarenko, V.M. Puzikov, A.N. Shekhovtsov, A.A. Ananenko, Yu.A. Borodenko, B.V. Grinyov, Yu.S. Koz'min, V.A. Tarasov, Cryst. Rep. 54, 165 (2009).

[20] L. Bardelli, M. Bini, P.G. Bizzeti, L. Carraresi, F.A. Danevich, T.F. Fazzini, B.V. Grinyov, N.V. Ivannikova, V.V. Kobychev, B.N. Kropivyansky, P.R. Maurenzig, L.L. Nagornaya, S.S. Nagorny, A.S. Nikolaiko, A.A. Pavlyuk, I.M. Solsky, M.V. Sopinskyy, Yu.G. Stenin, F. Taccetti, V.I. Tretyak, Ya.V. Vasiliev, S.S. Yurchenko, Nucl. Instrum. Methods Phys. Res. A 569, 743 (2006).

[21] B.I. Lazoryak, A.A. Belik, S.Yu. Stefanovich, V.A. Morozov, A.P. Malakho, O.V. Baryshnikova, I.A. Leonidov, O.N. Leonidova, Dokl. Phys. Chem. 384, 144 (2002).
[22] P.H. Haumesser, R. Gaumé, B. Viana, D. Vivien, J. Opt. Soc. Am. B 19, 2365 (2002).

[23] B.I. Lazoryak, Russ. Chem. Rev. 65, 287 (1996).

[24] I.A. Leonidov, M.Ya. Khodos, A.A. Fotiev, A.S. Zhukovskaya, Inorg. Mater. 24, 347 (1988) (in Russian).

[25] Z.B. Lin, G.F. Wang, L.H. Zhang, J. Cryst. Growth 304, 233 (2007).

[26] X. Hu, X. Chen, N. Zhuang, R. Wang, J. Chen, J. Cryst. Growth 310, 5423 (2008).

[27] L. Li, G. Wang, Y. Huang, L. Zhang, Z. Lin, G. Wang, J. Cryst. Growth 314, 331 (2011).

[28] M.V. Dobrotvorskaya, Yu.N. Gorobets, M.B. Kosmyna, P.V. Mateichenko, B.P. Nazarenko, V.M. Puzikov, A.N. Shekhovtsov, Cryst. Rep. 57, 86 (2012).

[29] B.M. Walsh, J.M. McMahon, W.C. Edwards, N.P. Barnes, R.W. Equall, R.L. Hutcheson, J. Opt. Soc. Am. B 19, 2893 (2002).

[30] Yu.A. Zagoruiko, V.K. Komar, M.B. Kosmyna, N.O. Kovalenko, B.P. Nazarenko, A.N. Shekhovtsov, in: Crystal Materials for Optics and Electronics, Ed. V.M. Puzikov, ISC Press, Kharkov 2012, p. 476 (in Russian). 